\title{
Pericytes Across the Lifetime in the Central Nervous System
}

\author{
Hannah C. Bennett and Yongsoo Kim* \\ Department of Neural and Behavioral Sciences, Penn State University, Hershey, PA, United States
}

The pericyte is a perivascular cell type that encapsulates the microvasculature of the brain and spinal cord. Pericytes play a crucial role in the development and maintenance of the blood-brain barrier (BBB) and have a multitude of important functions in the brain. Recent evidence indicates that pericyte impairment has been implicated in neurovascular pathology associated with various human diseases such as diabetes mellitus, Alzheimer's disease (AD), and stroke. Although the pericyte is essential for normal brain function, knowledge about its developmental trajectory and anatomical distribution is limited. This review article summarizes the scientific community's current understanding of pericytes' regional heterogeneity in the brain and their changes during

OPEN ACCESS

Edited by:

Miao He,

Fudan University, China

Reviewed by:

Berislav Zlokovic,

University of Southern California, United States

Xiaoqun Wang,

Chinese Academy of Sciences, China

Brad A. Sutherland,

University of Tasmania, Australia

*Correspondence: Yongsoo Kim yuk17@psu.edu

Specialty section: This article was submitted to Non-Neuronal Cells,

a section of the journal

Frontiers in Cellular Neuroscience

Received: 09 November 2020 Accepted: 23 February 2021

Published: 12 March 2021

Citation:

Bennett HC and Kim Y

(2021) Pericytes Across the Lifetime

in the Central Nervous System.

Front. Cell. Neurosci. 15:627291. doi: 10.3389/fncel.2021.627291 major life stages. More specifically, this review article focuses on pericyte differentiation and migration during brain development, regional population differences in the adult brain, and changes during normal and pathological aging. Most of what is known about pericytes come from studies of the cerebral cortex and hippocampus. Therefore, we highlight the need to expand our understanding of pericyte distribution and function in the whole brain to better delineate this cell type's role in the normal brain and pathological conditions.

Keywords: pericyte, brain, development, aging, blood brain barrier, regional heterogeneity, mouse

\section{INTRODUCTION}

Pericytes are a mural cell type that are highly abundant in the microvasculature in the central nervous system (CNS). These cells are tightly associated with the brain's blood vessels and form one of the major components of the blood-brain barrier (BBB). The $\mathrm{BBB}$, which forms during the embryonic and early postnatal period of development in mice, is comprised of endothelial cells, pericytes, and their shared basement membrane, as well as astrocytic endfeet (Ballabh et al., 2004). In humans, the development of the $\mathrm{BBB}$ corresponds to preterm infant development, or up to 32 weeks' gestation (Semple et al., 2013). The BBB is crucial for regulating substances transported between the vessel lumen and the brain parenchyma and provides the nutrients, water, and oxygen required

Abbreviations: aminopeptidase N, CD13; CNS, central nervous system; BBB, blood-brain barrier; PDGFR $\beta$, platelet-derived growth factor receptor $\beta$; PDGF- $\beta$, platelet-derived growth factor $\beta$; NG2, neural glial antigen 2 ; vSMC, vascular smooth muscle cell; VEGF, vascular endothelial growth factor; VEGFR1, vascular endothelial growth factor receptor 1; TGF $\beta$, transforming growth factor $\beta$; FoxF2, forkhead box F2; Mfsd2a, endothelial major facilitator superfamily domain-containing 2a; postnatal day \#, P\#; embryonic day \#, E\#; AD, Alzheimer's disease; APP, amyloid precursor protein; Amyloid $\beta, A \beta$; LRP1, low-density receptor-related protein 1; APOE4, apolipoprotein E4; sPDGFR $\beta$, soluble PDGFR $\beta$. 
for proper brain function (Ballabh et al., 2004). Pericytes, in particular, form lock and socket junctions with endothelial cells and contribute significantly to the maintenance of the BBB (Gökçinar-Yagci et al., 2015). Various markers have been used to label pericytes, such as platelet-derived growth factor receptor $\beta$ (PDGFR $\beta$ ), neural glial antigen 2 (NG2), desmin, and aminopeptidase N (CD13; Birbrair, 2019; Brown et al., 2019). However, these markers are also expressed in other cell types, posing challenges in clearly labeling pericytes (Bondjers et al., 2006; Attwell et al., 2016). Moreover, pericytes have additional functions pertaining to toxin clearance, cytokine and chemokine production, as well as capillary blood flow regulation (Bell et al., 2010; Kamouchi et al., 2011; Gökçinar-Yagci et al., 2015; Sweeney et al., 2016; Trost et al., 2016; Brown et al., 2019). Several excellent reviews have recently summarized current evidence relating to the importance of pericytes, as well as their identification and versatile functions (Sims, 2000; Bergers and Song, 2005; Bell et al., 2010; Kamouchi et al., 2011; Gökçinar-Yagci et al., 2015; Attwell et al., 2016; Trost et al., 2016; Yamazaki and Mukouyama, 2018; Brown et al., 2019; Coelho-Santos and Shih, 2020). By analyzing the topics of embryonic and postnatal pericyte development, differences in brain regional vulnerability, as well as $\mathrm{BBB}$ and pericyte changes in normal and pathological aging, this review seeks to not only provide an integrated view of current knowledge but also emphasizes the need to further study pericyte populations across multiple brain regions to better delineate their roles in human disease.

\section{EMBRYONIC PERICYTE DEVELOPMENT AND MIGRATION}

BBB development, particularly that involves pericyte differentiation and migration, begins embryonically for both humans and rodents (Armulik et al., 2005). Most of what is known regarding CNS pericyte development is gleaned primarily from rodent studies in the brain and the retina. Although spinal cord pericyte development is also crucial for neurovascular development, potential differences between brain and spinal cord pericytes are largely understudied and both populations are presumed to be similar (Bartanusz et al., 2011; Picoli et al., 2019). CNS pericytes are thought to be primarily derived from the neural crest and mesenchymal cell lineages (Prazeres et al., 2018). However, a subset of the embryonic CNS pericyte population may arise from other sources, such as blood-borne macrophages (Yamamoto et al., 2017). At approximately embryonic day 10 (E10) of mouse development, there are hematopoietic lineage cells $\left(\mathrm{CD} 31^{+} \mathrm{F} 4 / 80^{+}\right)$containing well-known macrophage markers in the avascular region near the developing midbrain (Yamamoto et al., 2017). This particular subset of macrophages was tracked to the subventricular vascular plexus, within which they differentiated into cells expressing classic pericyte markers, including NG2, PDGFR $\beta$, and desmin, and wrapped around the growing microvasculature (Yamamoto et al., 2017). Thus, the lineage of pericytes in the brain, and the CNS in general, may be heterogeneous (Figure 1A). Although the source of this cell type may vary, several studies have investigated the coordinated and essential roles of pericytes in the development of the neurovascular system (Armulik et al., 2005, 2011; Bergers and Song, 2005; Nakagomi et al., 2015).

Vascularization of the mouse brain is thought to begin at approximately E9.5 based on studies of the hindbrain, forebrain, and retina (Armulik et al., 2005, 2011; Paredes et al., 2018). In the spinal cord, vascularization begins slightly earlier, and current understanding of this process as well as differences between the $\mathrm{BBB}$ and blood spinal cord barrier have recently been reviewed (Bartanusz et al., 2011; Paredes et al., 2018; Picoli et al., 2019). Endothelial growth is largely driven by vascular endothelial growth factor (VEGF) signaling with the majority of mural cell precursors arising from the neural crest at around E10.5 (Armulik et al., 2005; Paredes et al., 2018). PDGFR $\beta$ is a receptor for the primary signaling growth factor for pericytes and is crucial for the migration and survival of these cells (Sweeney et al., 2016). PDGFR $\beta$ can be activated by both PDGF-B and PDGF-D isoforms, for which the ligand PDGF-B is primarily produced by endothelial cells (Sweeney et al., 2016). From E11.5 through E14, PDGF-B signaling plays an important role at all levels of the developing vasculature to help drive pericyte migration (Hellström et al., 2001). By E18.5 this expression is limited to capillaries, which then become a major site of pericyte cell density (Hellström et al., 2001). Also, there are several other pathways associated with the migration of these cells. For example, endothelial-derived transforming growth factor $\beta$ (TGF $\beta$ ) signaling and downstream components, such as Alk5/SMAD2/3, have been shown to play a role in the differentiation of pericytes, as well as the formation of the classic peg and socket junctions between pericytes and endothelial cells (Dave et al., 2018). The associated Alk5/Timp3 pathway in pericytes contributes to endothelial morphogenesis and regulation of basement membrane formation during embryonic development (Dave et al., 2018). TGF $\beta$ is also known to drive the incorporation of vascular smooth muscle cells (vSMCs) into larger arteries and venules (Allinson et al., 2012). Also, angiopoietin 1-Tie2 signaling mediates intercommunication between developing endothelium and pericytes (Teichert et al., 2017). More recently, precursor neural crest cells expressing PDGFR $\beta$, described above, have also been shown to express forkhead box F2 (FoxF2; Reyahi et al., 2015). These cells are thought to comprise the precursors of mural cell types, including both pericytes and vSMCs (Armulik et al., 2005). FoxF2 is a factor that drives the development of mesenchymal cells of the gut, but it is also expressed by neural crest cells in brain development (Reyahi et al., 2015). The loss of FoxF2 perturbs the vascular system and $\mathrm{BBB}$ development by reducing TGF $\beta / \mathrm{Smad} 2 / 3$ signaling as well as PDGFR $\beta$ expression (Reyahi et al., 2015). This indicates that FoxF2 plays a major role in the regulation of pericyte development as it has an impact on pathways essential for pericyte growth, differentiation, and survival. Additionally, molecules such as Gpr124, Zo1 , Notch, and others have also been implicated in pericyte and vascular development (Armulik et al., 2011; Wang et al., 2014; Yamazaki and Mukouyama, 2018; Zaitoun et al., 2019). Many of these signaling pathways associated with pericyte development are summarized in Figure 1B. Despite such a short developmental period, the BBB becomes functional by age 


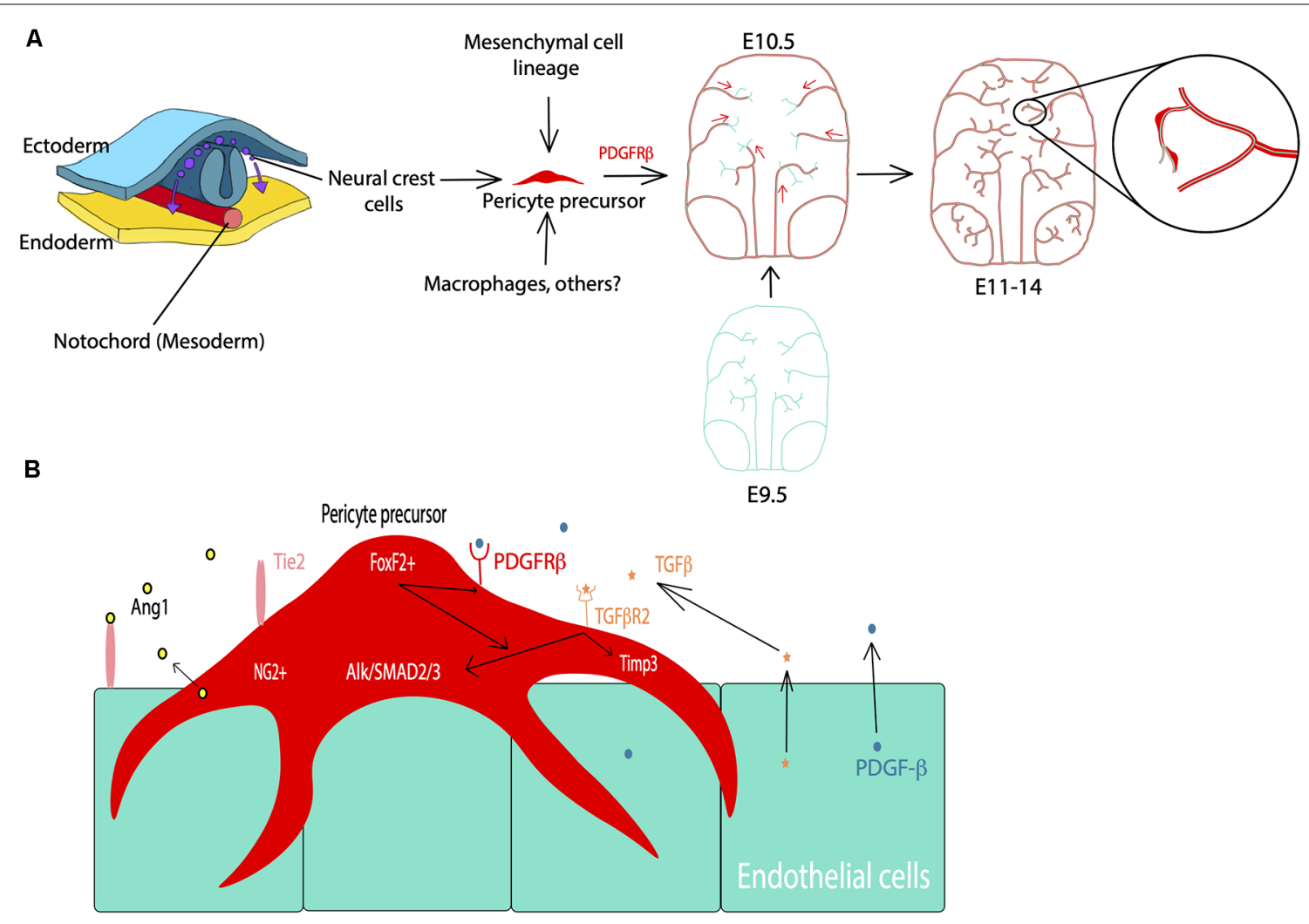

FIGURE 1 | Pericyte development during the embryonic period. (A) Cell lineage of pericytes including neural crest cells, mesenchymal cells, and macrophages. PDGFR $\beta$ signaling facilitates pericyte migration during embryonic development starting at E10.5 in mice. Cyan: endothelial cells, Red: pericytes. (B) Examples of the major players in pericyte-endothelial interactions during embryonic development such as PDGFR $\beta$ signaling for pericyte development and migration, TGF $\beta$ signaling, Alk/SMAD2/3 and Timp3 signaling for pericyte-endothelial junctions and basement membrane formation, and FoxF2 for mediating PDGFR $\beta$ and TGF $\beta$ signaling during development.

E15.5 in mice and E17 in rats due to highly regulated pericyteendothelial interactions (Daneman et al., 2010; Ben-Zvi et al., 2014). Although this structure is considered to be functional, its development is not quite finished at birth (Obermeier et al., 2013). In essence, pericytes play crucial roles in early vascular development, particularly by influencing the formation of the $\mathrm{BBB}$ and endothelial growth which are essential for proper neurovascular development.

\section{POSTNATAL PERICYTE DEVELOPMENT}

Following embryonic developmental migration and formation of the $\mathrm{BBB}$, the microvasculature begins to mature in the early postnatal period in rodents (Figure 2), corresponding to the late gestational period in humans. After birth, endothelial cells show sharp proliferation to expand the vascular network which peaks at postnatal day 10 (P10) and drops by P25 (Harb et al., 2013). This is particularly apparent in the gray matter where the vascular density doubles by P20 and has a much higher pericyte density than the white matter (Zeller et al., 1996). Similarly, vascular branching increases around P10 and appears more similar to the adult brain by P25 (Harb et al., 2013). Alternatively, pericyte proliferation begins to decline in the postnatal period, while pericyte coverage of the vasculature continues to expand (Harb et al., 2013). Although pericyte proliferation is not as pronounced, pericyte coverage and vessel stability continue to mature during this period (Harb et al., 2013). By P1 in the mouse brain, pericytes have transitioned to partial coverage resembling that of adult pericyte morphology (Daneman et al., 2010; Obermeier et al., 2013). Additionally, pericyte expression of certain factors is crucial for proper development during this period. For example, loss of the pericyte-derived RBPJ transcription factor results in increased BBB permeability, excess TGF $\beta$ activation, cavernous malformations, and impaired vascular integrity (Diéguez-Hurtado et al., 2019). Finally, pericytes themselves are not mature until the postnatal period, as they do not begin to express CD13 until around P6 (Jung et al., 2018).

The BBB undergoes further maturation in the early postnatal period through the further attachment of astrocytic endfeet, with regulation and maintenance provided by pericytes and endothelial cells (Ma et al., 2012). Many of the factors that initiate the formation of vascular development in utero continue to refine these processes during the early postnatal period. For example, pericyte-expressed Tie2 plays an instrumental role in retinal angiogenesis, as Tie2 deletion delays postnatal angiogenesis 


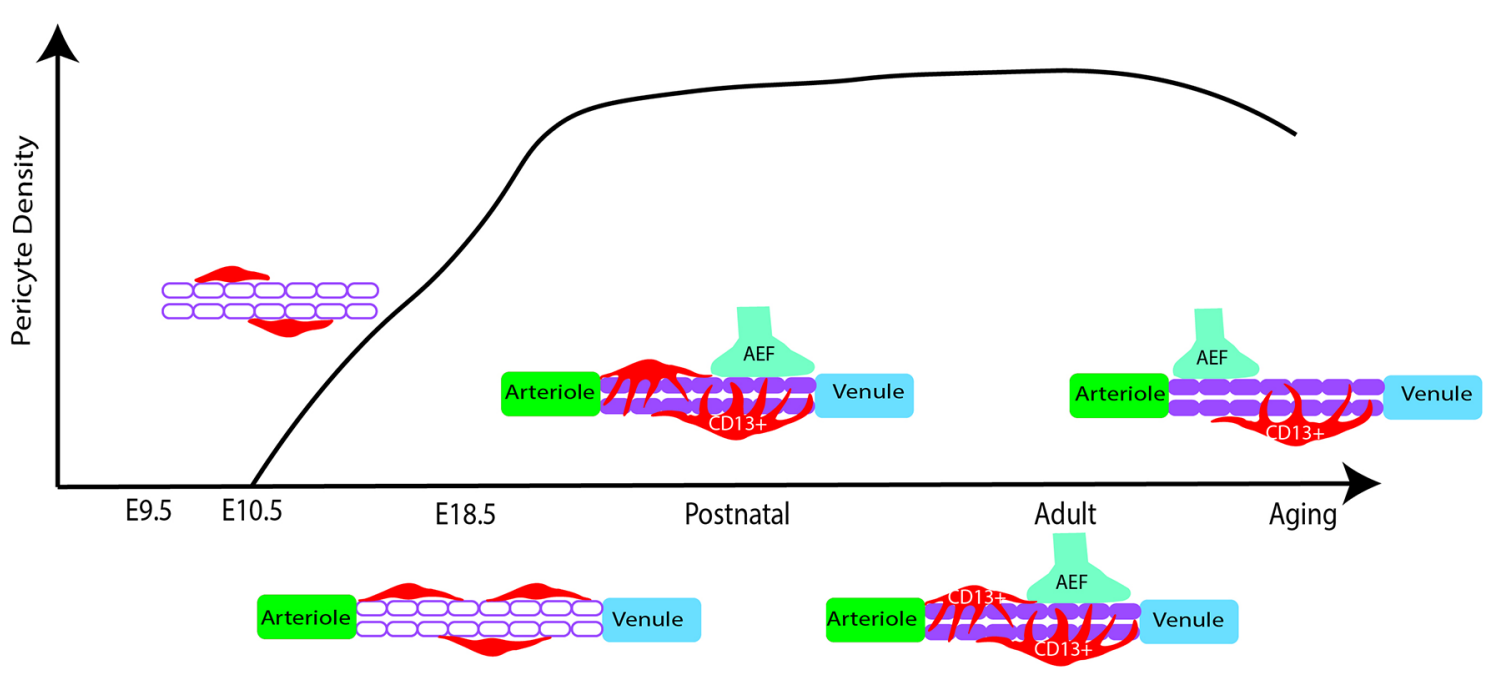

FIGURE 2 | Pericyte density changes from early embryonic development to aging in mice. At E10.5 pericyte precursors are present and begin to migrate and develop along the developing vasculature. In late embryonic development, there is increased proliferation of pericytes, showing a higher density of cells in the capillaries. During early postnatal development, proliferation subsides while increased pericyte coverage of capillaries contributes to vessel stability. Pericytes also appear more similar to adult morphology. Astrocytic end feet (AEF) properly attach and contribute to brain barrier (BBB) maturation during this period. In adulthood, the population density is rather stable while there are differences by brain region. Finally, possible pericyte loss during aging. Red: pericyte, Purple: microvessel.

and confers a migratory pericyte phenotype (Teichert et al., 2017). Additionally, PDGF-B/PDGFR $\beta$ signaling continues to promote pericyte survival and coverage of the microvasculature (Lindahl et al., 1997; Nikolakopoulou et al., 2017). There is also evidence to suggest pericytes regulate and guide postnatal endothelial expansion. This is particularly evident in the restriction of VEGF-induced endothelial sprouting, through the pericyte expression of VEGF receptor 1 (Darden et al., 2019). When VEGFR1 is specifically knocked out in pericytes there is an enlargement of vessels and associated angiogenic defects (Darden et al., 2019). Moreover, pericytes further facilitate endothelial function and $\mathrm{BBB}$ integrity through regulation of a key $\mathrm{BBB}$ regulator called endothelial major facilitator superfamily domain-containing 2a (Mfsd2a) expression, which serves to suppress transcytosis in these cells (Ben-Zvi et al., 2014). Loss of this BBB-specific protein serves to perturb tight junctions and increase endothelial transcytosis (Ben-Zvi et al., 2014). The above is only a snapshot of this concerted effort to develop and mature the $\mathrm{BBB}$ but also provides context for the important role pericytes play in this process. However, there are still gaps in our knowledge of these vascular developmental processes, and how this relates to neurodevelopmental disorders. For example, what is an underlying mechanism to regulate pericyte density in the early postnatal period? Do pericytes undergo a pruning stage of postnatal development that is similar to endothelial cells and neurons? How might disturbed processes in vascular development relate to neurodevelopmental disorders? Although there is much more to investigate, this vascular growth trajectory is important for understanding how the brain develops and how this development progresses in parallel with neuronal development. For further reading, the development of cerebrovascular structure and the neurogliovascular unit during the postnatal period was recently summarized in several excellent reviews (Paredes et al., 2018; Coelho-Santos and Shih, 2020).

\section{REGIONAL DIFFERENCES OF THE PERICYTE AND ASSOCIATED VULNERABILITY IN THE ADULT CNS}

Pericytes are present in most regions of the adult CNS and yet the distribution of this cell population and its associated characteristics are a major area of exploration. Although several studies have utilized in vivo 2-photon imaging and immunohistochemical methods to study these cells during development, aging, and disease pathology, very few studies have described pericyte population differences across brain regions of the adult mouse CNS, let alone in humans. However, pericyte populations are likely to be variable across different tissues and organs (Sims, 2000). Studies of wild-type mice demonstrate that pericyte density is decreased in the spinal cord compared to the brain, with regional variations between spinal cord levels (Winkler et al., 2012). Major challenges associated with investigating pericyte population variability, particularly in the brain, include a lack of specific cellular markers for pericytes, controversy in the field about pericyte classification, and technological limitations in quantitative cell type brain mapping (Sims, 2000; Attwell et al., 2016; Yamamoto et al., 2017). The use of transgenic PDGFR $\beta$-Cre and NG2-Cre mouse lines has helped to demonstrate that pericytes are generally present throughout the whole mouse brain (Hartmann et al., 2015). Additionally, pericyte distribution differs by cortical layer within the cerebral cortex, indicating that these cells may not be uniformly located along the vasculature (Hartmann et al., 2015). The morphology of these cells can vary as well (Sims, 2000; 
Hartmann et al., 2015; Berthiaume et al., 2018). For example, pericytes within the cerebral cortex can accommodate several morphologies, including the classical en passant or helical pericyte, as well as mesh pericytes which are more difficult to visually distinguish from vSMCs (Hartmann et al., 2015). Moreover, pericyte subtypes with different morphologies cover different vascular territories (Grant et al., 2019). These different pericyte morphologies and the terms used to categorize them have been recently described (Berthiaume et al., 2018). The phenotypic and molecular differences between pericytes and other mural cells have been further explored thanks to advances in single-cell RNA sequencing (Vanlandewijck et al., 2018; Zeisel et al., 2018). There seems to be a continuum in the transitions between different types of mural cells across the vasculature, in which the transition from arteriolar vSMCs to pericytes can occur between neighboring cells (Vanlandewijck et al., 2018; Grant et al., 2019). Additionally, transcriptional differences exist between arteriolar- and venule-associated vSMCs, as well as pericytes. However, there appears to be a lack of transcriptional heterogeneity within the pericyte population itself (Vanlandewijck et al., 2018).

Of course, it is necessary to note that this uniformity also depends on the definition of the pericyte that is used, which remains intensely debated in the field (Attwell et al., 2016). For example, the inclusion of smooth muscle actin-expressing contractile PDGFR $\beta$ + cells located within the arteriolar branches of the capillary bed as pericytes may expand the transcriptional diversity of this cell population (Hall et al., 2014; Attwell et al., 2016). Additionally, another transcriptomic study indicates that there are three pericyte subtypes with type 1 being the most numerous throughout the brain while type 3 pericytes are more similar to vascular smooth muscle cells, as per their respective expression profiles (Zeisel et al., 2018). To complicate things further, studies continue to demonstrate that pericytes, even capillary pericytes, may also have vasomotor functions to regulate cerebral blood flow and neurovascular coupling (Alarcon-Martinez et al., 2020; Nelson et al., 2020). Recently, a pericyte-specific mouse model was developed using a double promoter method to exclusively label pericytes and to highlight the catastrophic effects of pericyte ablation (Nikolakopoulou et al., 2019). This new animal model will help to further delineate the complicated categorization of pericytes in the future. Additional comprehensive transcriptomic and cell-type mapping studies can also help to develop a more well-rounded definition of the pericyte by uncovering specific characteristics of this intriguing and rather unique cell population.

Pericytes have heterogeneous vulnerability across regions of the CNS in pathological conditions as well. For example, a study using Pdgfr $\beta^{\mathrm{F} 7 / \mathrm{F} 7}$ mice, a model of pericyte deficiency, showed that there are regional differences in pericyte loss, capillary length reductions, and BBB breakdown (Nikolakopoulou et al., 2017). Importantly, these losses occurred much earlier and more significantly in the somatosensory cortex and hippocampus, while the thalamus and striatum were less affected (Nikolakopoulou et al., 2017). Although vSMCs also express PDGFR $\beta$, these populations appeared to be less affected at time points in which pericyte loss was already present
(Nikolakopoulou et al., 2017). This could indicate that there is a difference in the vulnerability of cortical vs. subcortical pericyte populations. The use of a similar mouse model of pericyte deficiency showed that there is also BBB permeability heterogeneity by region upon pericyte loss (Villaseñor et al., 2017). In this study, there was increased BBB permeability, measured by both Evan's blue dye and IgG leakage, in the areas of the cortex, striatum, and hippocampus, while areas such as the cerebellum and midbrain were less prominent (Villaseñor et al., 2017). Importantly, this difference was not due to differences in local pericyte coverage or changes in tight junction integrity (Villaseñor et al., 2017). The reasons behind this regional difference in permeability following significant pericyte loss should be further explored. Many of the above findings are summarized in Figure 3. Also, pericytes appear to be more susceptible to ischemic injury compared to endothelial cells in both the gray and white matter of rat neocortical and cerebellar brain slices, respectively (Hall et al., 2014). This susceptibility is not limited to the brain, as pericytes in the spinal cord are also quite heterogeneous and implicated in several pathologies (Bartanusz et al., 2011; Almeida et al., 2018; Picoli et al., 2019). In fact, in studies of Amyotrophic Lateral Sclerosis (ALS), there is evidence of pericyte dysfunction and loss in particular regions of the spinal cord such as the ventral horn (Winkler et al., 2013; Yamadera et al., 2015). Moreover, pericytes have been a focus of study in spinal cord injury due to their role as a potential therapeutic target and pericyte Glast-expressing subtype involvement in scar formation in response to injury (Almeida et al., 2018; Picoli et al., 2019). Differences in cell lineage and normal behaviors associated with these spinal cord pericyte subtypes would be invaluable to expanding the field's understanding of this population. Summarization of this pericyte heterogeneity in the spinal cord is also shown in Figure 3. This CNS pericyte vulnerability and evidence of cell loss suggest that there are cell-specific and regional differences in terms of microvascular vulnerability to injury or disease. However, several questions about CNS pericyte populations remain. How do pericyte morphology, function, and regional vulnerability differ if the population seems to be transcriptionally uniform? Are there fewer pericytes in circumventricular organs, as would be expected given the known "leakiness" of these brain regions (Wilhelm et al., 2016)? How do spinal cord pericytes differ from brain pericytes in terms of their cell lineage? One thing is certain, further studies are required to better understand pericyte and mural cell populations in general.

\section{BBB AND PERICYTE CHANGES IN NORMAL AGING}

Given the apparent evidence for pericyte vulnerability, it is possible that aging may influence the $\mathrm{BBB}$ and pericyte population changes. Aging itself is rather complex and further complicated by diseases that seem to be inextricably linked to the aging process in humans. Some of these pathologies include dementia, a vast array of cerebrovascular diseases, endocrine diseases, and autoimmune disorders. Not only does aging affect the body systemically, but it also has implications 


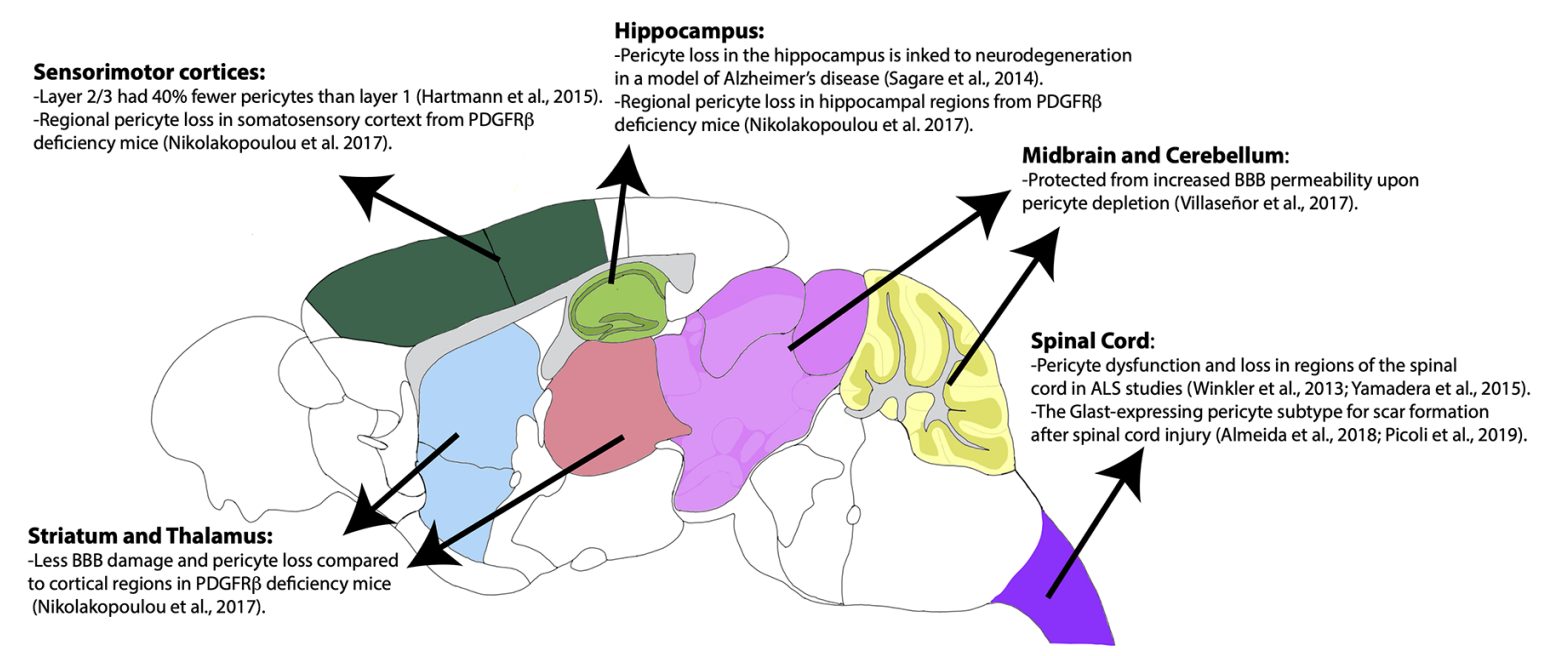

FIGURE 3 | Regional heterogeneity of pericyte distribution and vulnerabilities. Brain regions are color-coded according to the Allen Mouse Brain Atlas. Brain regions with heterogenous distribution and vulnerability are highlighted.

within the brain. Aging is known to have a multitude of effects on neuronal and glial cells, including DNA damage, morphological changes, activation of inflammatory cascades, and impairments in function, which have been recently reviewed (Knox, 1982; Peters et al., 1991; Palmer and Ousman, 2018; Valles et al., 2019). Studies also indicate that aging may contribute to changes in the neurovasculature and the BBB ( $\mathrm{Li}$ et al., 2019). This is often linked to the consistent finding of chronic inflammation that develops during aging, typically referred to as immunoaging (Fjell et al., 2014; Palmer and Ousman, 2018; Valles et al., 2019). For example, in C57 mice aged 24 months, there is increased BBB permeability and elevated neurovascular inflammation in hippocampal and cortical regions when compared to young controls (Jansson et al., 2014; Duan et al., 2018). Furthermore, changes in inflammatory molecule expression during normal aging lead to loss of tight junction integrity and increased BBB leakiness (Jansson et al., 2014; Duan et al., 2018). The findings of this study support previous work in humans showing that healthy participants greater than 60 years of age had increased BBB permeability (Farrall and Wardlaw, 2009). Additionally, an MRI study found that even individuals without cognitive impairment had age-dependent decreases in $\mathrm{BBB}$ integrity in the hippocampus, particularly the dentate gyrus and CA1 region, while other cortical and subcortical regions were less affected (Montagne et al., 2015). Evidence of these age-related neurovascular changes in humans is particularly striking, especially when considering that this may be occurring in normal aging. Finally, a notable study showed that even aside from $\mathrm{BBB}$ leakiness, there is an age-related shift in transcytosis at the $\mathrm{BBB}$, involving a decrease in receptor-mediated transport, which can heavily influence brain homeostasis (Yang et al., 2020). This study also suggested that this age-related change in transcytosis may be influenced by pericyte loss (Yang et al., 2020). Needless to say, the impacts of aging on the BBB are likely to be due to changes in its components.
There is also evidence to suggest that aging is also associated with changes in CNS pericyte populations themselves, as well as their functions and interactions with other cell types. Even in the absence of pathological states, aging in mice is associated with pericyte dysfunction (Peters et al., 1991; Hughes et al., 2006; Elahy et al., 2015). Various studies indicate that during aging, pericytes may have impaired interactions with endothelial cells (Armulik et al., 2005; Hughes et al., 2006; Elahy et al., 2015). Moreover, aging-related pericyte dysfunction has been associated with mitochondrial, migratory, and phenotypic changes (Armulik et al., 2011; Erdö et al., 2017; Jackson et al., 2017; Yamazaki and Mukouyama, 2018). For example, studies have noted ultrastructural changes in these cells, such as lipofuscin inclusions, changes in mitochondrial size, increased smooth muscle expression, and overall changes to pericyte structure and morphology (Knox, 1982; Bar, 1985; Peters et al., 1991; Hughes et al., 2006; Elahy et al., 2015). A more severe change in neurovascular function is pericyte loss, which has previously been suggested to occur in normal aging (Peters et al., 1991; Farrall and Wardlaw, 2009). Pericyte loss is well known to have detrimental effects on BBB permeability, which could also explain compromised neurovascular regulation demonstrated in previous aging studies (Bell and Zlokovic, 2009; Bell et al., 2010; Elahy et al., 2015). Additionally, pericyte loss impacts the microcirculation within the brain, leading to oxidative stress and hypoxia in these oxygen-starved areas (Bell et al., 2010). However, pericyte loss upon aging remains controversial, as pericyte populations appeared to be similar when compared in 2-month-old and 22-month-old mice, according to a recent transcriptomic study (Ximerakis et al., 2019). Of course, it is important to keep in mind that this study does not account for potential subtypes or regional differences in this cell population. Therefore, it will be necessary to resolve this controversy to better distinguish changes in normal aging from those that occur in pathological processes. 
TABLE 1 | Pericyte involvement in human diseases.

\begin{tabular}{|c|c|c|c|}
\hline System & Disease & Associated regions & References \\
\hline \multirow[t]{2}{*}{ Neurological } & Epilepsy & Temporal lobe (most commonly) & Sweeney et al. (2018b) \\
\hline & Spinal cord injury & The spinal cord, CNS & $\begin{array}{l}\text { Bartanusz et al. (2011), Almeida et al. (2018), } \\
\text { Sweeney et al. (2018b) and Picoli et al. (2019) }\end{array}$ \\
\hline \multirow[t]{3}{*}{ Neurodegenerative } & Alzheimer's disease & $\begin{array}{l}\text { Hippocampus, entorhinal } \\
\text { cortex, basal forebrain }\end{array}$ & $\begin{array}{l}\text { Girouard and ladecola (2006), Zlokovic (2008), } \\
\text { Bell and Zlokovic (2009), Armulik et al. (2011), } \\
\text { Winkler et al. (2011), Baloyannis and Baloyannis } \\
\text { (2012), Rosenberg (2014), } \\
\text { Di Marco et al. (2015), Lane-Donovan and Herz } \\
\text { (2017), Newcombe et al. (2018), } \\
\text { Sweeney et al. (2018a), Lendahl et al. (2019), } \\
\text { Nation et al. (2019) and Montagne et al. (2020) }\end{array}$ \\
\hline & Vascular dementia & $\begin{array}{l}\text { Commonly vascular regions of } \\
\text { the middle cerebral artery }\end{array}$ & $\begin{array}{l}\text { Montagne et al. (2020), Moretti and Caruso } \\
\text { (2020) and Uemura et al. (2020) }\end{array}$ \\
\hline & Parkinson's disease & Substantia nigra pars compacta & $\begin{array}{l}\text { Erdö et al. (2017), Sweeney et al. (2018b) and Li } \\
\text { et al. (2019) }\end{array}$ \\
\hline \multirow{3}{*}{ Cardiovascular } & Hypertension & $\begin{array}{l}\text { The vascular territory of the } \\
\text { middle cerebral artery }\end{array}$ & $\begin{array}{l}\text { Knox (1982), Girouard and ladecola (2006) } \\
\text { and Hirunpattarasilp et al. (2019) }\end{array}$ \\
\hline & Small vessel disease & Microvasculature & $\begin{array}{l}\text { Hogan and Feeney (1963), } \\
\text { Neurology Working Group of the Cohorts for } \\
\text { Heart and Aging Research in Genomic } \\
\text { Epidemiology (CHARGE) Consortium, the } \\
\text { Stroke Genetics Network (SiGN) and the } \\
\text { International Stroke Genetics Consortium } \\
\text { (ISGC) (2016) and Moretti and Caruso (2020) }\end{array}$ \\
\hline & Stroke, Ischemia & Several CNS regions & $\begin{array}{l}\text { Girouard and ladecola (2006), Lucke-Wold et al. } \\
\text { (2014), } \\
\text { Neurology Working Group of the Cohorts for } \\
\text { Heart and Aging Research in Genomic } \\
\text { Epidemiology (CHARGE) Consortium, the } \\
\text { Stroke Genetics Network (SiGN) and the } \\
\text { International Stroke Genetics Consortium } \\
\text { (ISGC) (2016) and Hu et al. (2017) }\end{array}$ \\
\hline Immunological & General neuroinflammation & Blood-brain barrier (BBB) & $\begin{array}{l}\text { Jansson et al. (2014), Persidsky et al. (2016), } \\
\text { Rustenhoven et al. (2017) and Newcombe et al. } \\
\text { (2018) }\end{array}$ \\
\hline \multirow[t]{2}{*}{ CNS Infection } & Viral: HIV, CMV & BBB & $\begin{array}{l}\text { Nakagawa et al. (2012) and Bertrand et al. } \\
\text { (2019) }\end{array}$ \\
\hline & Bacterial infections & BBB & Guijarro-Muñoz et al. (2014) \\
\hline Cancer of the CNS & Glioblastoma/Glioma & BBB, midline cortical regions & Liebner et al. (2018) and Valdor et al. (2019) \\
\hline
\end{tabular}

\section{BBB AND PERICYTE DYSFUNCTION IN PATHOLOGICAL AGING}

Pathological states, particularly neurodegenerative diseases, have increased damage to the cerebral microvasculature and pericytes. Notably, increased BBB permeability and inflammation have been demonstrated in human patients with Alzheimer's disease (AD) and $\mathrm{AD}$ mouse models (Bell and Zlokovic, 2009; Halliday et al., 2016; Kisler et al., 2017; Brown et al., 2019). Given that these changes are also present in normal aging, it is likely that these pathological processes further compromise neurovascular function. For example, in the amyloid precursor protein (APP) overexpression mouse model of $\mathrm{AD}$, pericyte loss accelerated Amyloid $\beta(\mathrm{A} \beta)$ pathology and neurodegeneration with deteriorated memory performance (Sagare et al., 2013). Several studies have further demonstrated that pericyte deficiency is associated with neurodegeneration in both the gray and white matter of the brain (Bell et al., 2010; Montagne et al., 2018; Nikolakopoulou et al., 2019). Moreover, pericytes express pleiotrophin which is a neurotrophic growth factor that is crucial for neuronal health (Nikolakopoulou et al., 2019). This suggests that pericytes' roles may expand 
beyond $\mathrm{BBB}$ functions to directly contribute to neuronal health in the brain. Furthermore, this provides evidence that vascular and pericyte dysfunction occurs before neurons begin to show evidence of damage and cell loss. Additionally, $\mathrm{A} \beta$ oligomers have been shown to signal to pericytes, thereby causing capillary constriction (Nortley et al., 2019). This demonstrates a crucial link between the toxic accumulation of cellular byproducts and associated neurovascular dysfunction. Moreover, pericytes are known to clear $\mathrm{A} \beta$ through receptormediated endocytosis, involving the low-density receptor-related protein 1 (LRP1), which is an important protein in $A \beta$ homeostasis at the BBB (Shibata et al., 2000; Ma et al., 2018). Clearly, pericytes are instrumental in the regulation of $\mathrm{A} \beta$ accumulation and may provide a key link in the pathophysiology of AD.

Importantly, apolipoprotein E4 (APOE4), which is a major susceptibility factor for the development of $\mathrm{AD}$ has also been linked to $\mathrm{BBB}$ dysfunction and injury to pericytes in both $\mathrm{AD}$ models and in human carriers (Lane-Donovan and Herz, 2017; Uddin et al., 2019; Montagne et al., 2020). For instance, APOE4 is linked to $\mathrm{BBB}$ breakdown through the activation of a proinflammatory cascade in pericytes through upregulation of the cyclophilin A-mediated nuclear factor $\kappa \mathrm{B}$ matrix metalloproteinase-9 pathway (Bell et al., 2012; Halliday et al., 2016). This not only helps to clarify the role of pericytes in neuroinflammatory states but could also relate to the inflammatory processes that are classically associated with $\mathrm{AD}$ pathology. Recently, APOE4 carriers were shown to have increased evidence of pericyte injury, measured by soluble PDGFR $\beta$ (sPDGFR $\beta$ ), which was predictive of cognitive decline independent of $\mathrm{A} \beta$ and pTau status (Sagare et al., 2015; Sweeney et al., 2015; Nation et al., 2019; Montagne et al., 2020). Moreover, a new method for detecting sPDGFR $\beta$ in both the plasma and cerebrospinal fluid can be clinically useful for identifying pericyte injury in neurovascular diseases (Sweeney et al., 2020). These studies further support that pericytes have an important role in neurodegenerative disease and spark additional questions relating to the role of pericytes in AD. Furthermore, pericyte loss has long been associated with diabetic retinopathy and diabetes mellitus is known to be a major risk factor for the development of AD (Pfister et al., 2008, 2010; Hayden, 2019). It is not surprising to think that neurovascular dysfunction likely serves as a unifying factor in the development of these disease processes. It would be intriguing to know whether the sPDGFR $\beta$ marker for pericyte injury could also be identified in other diseases associated with neurovascular dysfunction, such as diabetes, and how this could

\section{REFERENCES}

Alarcon-Martinez, L., Villafranca-Baughman, D., Quintero, H., Kacerovsky, J. B., Dotigny, F., Murai, K. K., et al. (2020). Interpericyte tunnelling nanotubes regulate neurovascular coupling. Nature 585, 91-95. doi: 10.1038/s41586-0202589-x

Allinson, K. R., Lee, H. S., Fruttiger, M., McCarty, J. H., McCarty, J., and Arthur, H. M. (2012). Endothelial expression of TGF $\beta$ type II receptor is required to maintain vascular integrity during postnatal development of the central nervous system. PLoS One 7:e39336. doi: 10.1371/journal.pone. 0039336 serve clinically to potentially identify patients with higher risk of cognitive decline. However, pericytes are not only implicated in $\mathrm{AD}$, as evidence relating to pericyte involvement in various human diseases has recently been described in several excellent reviews (Table $\mathbf{1}$ ).

\section{CONCLUSION}

The pericyte population of the brain is not static during our lifetime. These cells arise from heterogeneous sources and undergo significant cell proliferation and migration throughout embryonic development. Unlike other cell types, they have slowed proliferation in early postnatal stages, while also reaching their processes extensively across the microvasculature. Finally, in adulthood pericytes show varying morphologies and characteristics, and yet, this cell population is transcriptionally similar across the board. Moreover, mounting evidence continues to demonstrate the importance of these cells during the lifespan and in all regions of the mammalian brain. Pericytes are also becoming increasingly recognized for their potential roles in the pathophysiology of various human diseases, particularly those impacted by the aging process. With each new study, these mural cells become more intriguing and unique. To better understand this cell population and the brain vasculature as a whole, research cannot only be restricted to particular regions as this does not encompass the systemic impact of the brain vasculature.

\section{AUTHOR CONTRIBUTIONS}

$\mathrm{HB}$ and YK conceptualized the manuscript. HB wrote the initial manuscript draft and figures. YK handled the funding and critically revised the manuscript. All authors contributed to the article and approved the submitted version.

\section{FUNDING}

This publication was made possible by an NIH Blueprint for Neuroscience Research, NIH grant R01NS108407 to YK. Its contents are solely the responsibility of the authors and do not necessarily represent the views of the funding agency.

\section{ACKNOWLEDGMENTS}

We thank Rebecca Betty for her assistance in editing the manuscript.

Almeida, V. M., Paiva, A. E., Sena, I. F. G., Mintz, A., Magno, L. A. V., and Birbrair, A. (2018). Pericytes make spinal cord breathless after injury. Neuroscientist 24, 440-447. doi: 10.1177/1073858417731522

Armulik, A., Abramsson, A., and Betsholtz, C. (2005). Endothelial/pericyte interactions. Circ. Res. 97, 512-523. doi: 10.1161/01.RES.0000182903.16652.d7

Armulik, A., Genové, G., and Betsholtz, C. (2011). Pericytes: developmental, physiological, and pathological perspectives, problems, and promises. Dev. Cell 21, 193-215. doi: 10.1016/j.devcel.2011.07.001

Attwell, D., Mishra, A., Hall, C. N., O'Farrell, F. M., and Dalkara, T. (2016). What is a pericyte? J. Cereb. Blood Flow Metab. 36, 451-455 doi: $10.1177 / 0271678 \mathrm{X} 15610340$ 
Ballabh, P., Braun, A., and Nedergaard, M. (2004). The blood-brain barrier: an overview: structure, regulation, and clinical implications. Neurobiol. Dis. 16, 1-13. doi: 10.1016/j.nbd.2003.12.016

Baloyannis, S. J., and Baloyannis, I. S. (2012). The vascular factor in Alzheimer's disease: a study in Golgi technique and electron microscopy. J. Neurol. Sci. 322, 117-121. doi: 10.1016/j.jns.2012.07.010

Bar, T. (1985). Morphometric aspects of aging in central nervous system capillaries. Atti della Fondazione Giorgio Ronchi, 40, 471.

Bartanusz, V., Jezova, D., Alajajian, B., and Digicaylioglu, M. (2011). The bloodspinal cord barrier: morphology and clinical implications. Ann. Neurol. 70, 194-206. doi: 10.1002/ana.22421

Bell, R. D., Winkler, E. A., Sagare, A. P., Singh, I., LaRue, B., Deane, R., et al. (2010). Pericytes control key neurovascular functions and neuronal phenotype in the adult brain and during brain aging. Neuron 68, 409-427. doi: 10.1016/j.neuron. 2010.09.043

Bell, R. D., Winkler, E. A., Singh, I., Sagare, A. P., Deane, R., Wu, Z., et al. (2012). Apolipoprotein E controls cerebrovascular integrity via cyclophilin A. Nature 485, 512-516. doi: 10.1038/nature11087

Bell, R. D., and Zlokovic, B. V. (2009). Neurovascular mechanisms and bloodbrain barrier disorder in Alzheimer's disease. Acta Neuropathol. 118, 103-113. doi: 10.1007/s00401-009-0522-3

Ben-Zvi, A., Lacoste, B., Kur, E., Andreone, B. J., Mayshar, Y., Yan, H., et al. (2014). Mfsd2a is critical for the formation and function of the blood-brain barrier. Nature 509, 507-511. doi: 10.1038/nature13324

Bergers, G., and Song, S. (2005). The role of pericytes in blood-vessel formation and maintenance. Neuro Oncol. 7, 452-464. doi: 10.1215/S1152851705000232

Berthiaume, A. A., Hartmann, D. A., Majesky, M. W., Bhat, N. R., and Shih, A. Y. (2018). Pericyte structural remodeling in cerebrovascular health and homeostasis. Front. Aging Neurosci. 10:210. doi: 10.3389/fnagi.2018. 00210

Bertrand, L., Cho, H. J., and Toborek, M. (2019). Blood-brain barrier pericytes as a target for HIV-1 infection. Brain 142, 502-511. doi: 10.1093/brain/awy339

Birbrair, A. (Ed.). (2019). Pericyte Biology in Disease. Switzerland: Springer International Publishing. doi: 10.1007/978-3-030-16908-4

Bondjers, C., He, L., Takemoto, M., Norlin, J., Asker, N., Hellström, M., et al. (2006). Microarray analysis of blood microvessels from PDGF-B and PDGF$\mathrm{R} \beta$ mutant mice identifies novel markers for brain pericytes. FASEB J. 20, 1703-1705. doi: 10.1096/fj.05-4944fje

Brown, L. S., Foster, C. G., Courtney, J.-M., King, N. E., Howells, D. W., and Sutherland, B. A. (2019). Pericytes and neurovascular function in the healthy and diseased brain. Front. Cell. Neurosci. 13:282. doi: 10.3389/fncel.2019.00282

Coelho-Santos, V., and Shih, A. Y. (2020). Postnatal development of cerebrovascular structure and the neurogliovascular unit. Wiley Interdiscip. Rev. Dev. Biol. 9:e363. doi: 10.1002/wdev.363

Daneman, R., Zhou, L., Kebede, A. A., and Barres, B. A. (2010). Pericytes are required for blood-brain barrier integrity during embryogenesis. Nature 468, 562-566. doi: 10.1038/nature09513

Darden, J., Payne, L. B., Zhao, H., and Chappell, J. C. (2019). Excess vascular endothelial growth factor-A disrupts pericyte recruitment during blood vessel formation. Angiogenesis 22, 167-183. doi: 10.1007/s10456-018-9648-Z

Dave, J. M., Mirabella, T., Weatherbee, S. D., and Greif, D. M. (2018). Pericyte ALK5/TIMP3 axis contributes to endothelial morphogenesis in the developing brain. Dev. Cell 44, 665.e6-678.e6. doi: 10.1016/j.devcel.2018.01.018

Di Marco, L. Y., Venneri, A., Farkas, E., Evans, P. C., Marzo, A., and Frangi, A. F. (2015). Vascular dysfunction in the pathogenesis of Alzheimer's disease-A review of endothelium-mediated mechanisms and ensuing vicious circles. Neurobiol. Dis. 82, 593-606. doi: 10.1016/j.nbd.2015.08.014

Diéguez-Hurtado, R., Kato, K., Giaimo, B. D., Nieminen-Kelhä, M., Arf, H., Ferrante, F., et al. (2019). Loss of the transcription factor RBPJ induces disease-promoting properties in brain pericytes. Nat. Commun. 10:2817. doi: 10.1038/s41467-019-10643-w

Dore-Duffy, P., Owen, C., Balabanov, R., Murphy, S., Beaumont, T., and Rafols, J. A. (2000). Pericyte migration from the vascular wall in response to traumatic brain injury. Microvasc. Res. 60, 55-69. doi: 10.1006/mvre.2000.2244

Duan, L., Zhang, X.-D., Miao, W.-Y., Sun, Y.-J., Xiong, G., Wu, Q., et al. (2018). PDGFR $\beta$ cells rapidly relay inflammatory signal from the circulatory system to neurons via chemokine CCL2. Neuron 100, 183.e8-200.e8. doi: 10.1016/j. neuron.2018.08.030
Elahy, M., Jackaman, C., Mamo, J. C., Lam, V., Dhaliwal, S. S., Giles, C., et al. (2015). Blood-brain barrier dysfunction developed during normal aging is associated with inflammation and loss of tight junctions but not with leukocyte recruitment. Immun. Ageing 12:2. doi: 10.1186/s12979-015-0029-9

Erdö, F., Denes, L., and de Lange, E. (2017). Age-associated physiological and pathological changes at the blood-brain barrier: a review. J. Cereb. Blood Flow Metab. 37, 4-24. doi: 10.1177/0271678X16679420

Farrall, A. J., and Wardlaw, J. M. (2009). Blood-brain barrier: ageing and microvascular disease-systematic review and meta-analysis. Neurobiol. Aging 30, 337-352. doi: 10.1016/j.neurobiolaging.2007.07.015

Fjell, A. M., McEvoy, L., Holland, D., Dale, A. M., and Walhovd, K. B. (2014). What is normal in normal aging? Effects of aging, amyloid and Alzheimer's disease on the cerebral cortex and the hippocampus. Prog. Neurobiol. 117, 20-40. doi: 10.1016/j.pneurobio.2014.02.004

Girouard, H., and Iadecola, C. (2006). Neurovascular coupling in the normal brain and in hypertension, stroke, and Alzheimer disease. J. Appl. Physiol. 100, 328-335. doi: 10.1152/japplphysiol.00966.2005

Gökçinar-Yagci, B., Uçkan-Çetinkaya, D., and Çelebi-Saltik, B. (2015). Pericytes: properties, functions and applications in tissue engineering. Stem Cell Rev. Rep. 11, 549-559. doi: 10.1007/s12015-015-9590-Z

Grant, R. I., Hartmann, D. A., Underly, R. G., Berthiaume, A.-A., Bhat, N. R., and Shih, A. Y. (2019). Organizational hierarchy and structural diversity of microvascular pericytes in adult mouse cortex. J. Cereb. Blood Flow Metab. 39, 411-425. doi: 10.1177/0271678X17732229

Guijarro-Muñoz, I., Compte, M., Álvarez-Cienfuegos, A., Álvarez-Vallina, L. and Sanz, L. (2014). Lipopolysaccharide activates Toll-like receptor 4 (TLR4)-mediated NF- $\mathrm{BB}$ signaling pathway and proinflammatory response in human pericytes. J. Biol. Chem. 289, 2457-2468. doi: 10.1074/jbc.M113. 521161

Hall, C. N., Reynell, C., Gesslein, B., Hamilton, N. B., Mishra, A., Sutherland, B. A., et al. (2014). Capillary pericytes regulate cerebral blood flow in health and disease. Nature 508, 55-60. doi: 10.1038/nature13165

Halliday, M. R., Rege, S. V., Ma, Q., Zhao, Z., Miller, C. A., Winkler, E. A., et al. (2016). Accelerated pericyte degeneration and blood-brain barrier breakdown in apolipoprotein E4 carriers with Alzheimer's disease. J. Cereb. Blood Flow Metab. 36, 216-227. doi: 10.1038/jcbfm.2015.44

Harb, R., Whiteus, C., Freitas, C., and Grutzendler, J. (2013). in vivo imaging of cerebral microvascular plasticity from birth to death. J. Cereb. Blood Flow Metab. 33, 146-156. doi: 10.1038/jcbfm.2012.152

Hartmann, D. A., Underly, R. G., Grant, R. I., Watson, A. N., Lindner, V., and Shih, A. Y. (2015). Pericyte structure and distribution in the cerebral cortex revealed by high-resolution imaging of transgenic mice. Neurophotonics 2:041402. doi: 10.1117/1.NPh.2.4.041402

Hayden, . (2019). Type 2 diabetes mellitus increases the risk of late-onset Alzheimer's disease: ultrastructural remodeling of the neurovascular unit and diabetic gliopathy. Brain Sci. 9:262. doi: 10.3390/brainsci9100262

Hellström, M., Gerhardt, H., Kalén, M., Li, X., Eriksson, U., Wolburg, H., et al. (2001). Lack of pericytes leads to endothelial hyperplasia and abnormal vascular morphogenesis. J. Cell Biol. 153, 543-553. doi: 10.1083/jcb. 153.3.543

Hirunpattarasilp, C., Attwell, D., and Freitas, F. (2019). The role of pericytes in brain disorders: from the periphery to the brain. J. Neurochem. 150, 648-665. doi: $10.1111 /$ jnc. 14725

Hogan, M. J., and Feeney, L. (1963). The ultrastructure of the retinal vessels: II. The small vessels. J. Ultrastruct. Res. 9, 29-46. doi: 10.1016/s0022-5320(63)80034-9

Hu, X., De Silva, T. M., Chen, J., and Faraci, F. M. (2017). Cerebral vascular disease and neurovascular injury in ischemic stroke. Circ. Res. 120, 449-471 doi: 10.1161/CIRCRESAHA.116.308427

Hughes, S., Gardiner, T., Hu, P., Baxter, L., Rosinova, E., and Chan-Ling, T. (2006). Altered pericyte-endothelial relations in the rat retina during aging: implications for vessel stability. Neurobiol. Aging 27, 1838-1847. doi: 10.1016/j. neurobiolaging.2005.10.021

Jackson, S., ElAli, A., Virgintino, D., and Gilbert, M. R. (2017). Blood-brain barrier pericyte importance in malignant gliomas: what we can learn from stroke and Alzheimer's disease. Neuro Oncol. 19, 1173-1182. doi: 10.1093/neuonc/nox058

Jansson, D., Rustenhoven, J., Feng, S., Hurley, D., Oldfield, R. L., Bergin, P. S., et al. (2014). A role for human brain pericytes in neuroinflammation. J. Neuroinflammation 11:104. doi: 10.1186/1742-2094-11-104 
Jung, B., Arnold, T. D., Raschperger, E., Gaengel, K., and Betsholtz, C. (2018). Visualization of vascular mural cells in developing brain using genetically labeled transgenic reporter mice. J. Cereb. Blood Flow Metab. 38, 456-468. doi: $10.1177 / 0271678 X 17697720$

Kamouchi, M., Ago, T., and Kitazono, T. (2011). Brain pericytes: emerging concepts and functional roles in brain homeostasis. Cell. Mol. Neurobiol. 31, 175-193. doi: 10.1007/s10571-010-9605-x

Kisler, K., Nelson, A. R., Rege, S. V., Ramanathan, A., Wang, Y., Ahuja, A., et al. (2017). Pericyte degeneration leads to neurovascular uncoupling and limits oxygen supply to brain. Nat. Neurosci. 20, 406-416. doi: 10.1038/ nn. 4489

Knox, C. A. (1982). Effects of aging and chronic arterial hypertension on the cell populations in the neocortex and archicortex of the rat. Acta Neuropathol. 56, 139-145. doi: 10.1007/BF00690585

Lane-Donovan, C., and Herz, J. (2017). ApoE, ApoE receptors, and the synapse in Alzheimer's disease. Trends Endocrinol. Metab. 28, 273-284. doi: 10.1016/j. tem.2016.12.001

Laredo, F., Plebanski, J., and Tedeschi, A. (2019). Pericytes: problems and promises for CNS repair. Front. Cell. Neurosci. 13:546. doi: 10.3389/fncel.2019.00546

Lendahl, U., Nilsson, P., and Betsholtz, C. (2019). Emerging links between cerebrovascular and neurodegenerative diseases-a special role for pericytes. EMBO Rep. 20:e48070. doi: 10.15252/embr.201948070

Li, Y., Xie, L., Huang, T., Zhang, Y., Zhou, J., Qi, B., et al. (2019). Aging neurovascular unit and potential role of DNA Damage and repair in combating vascular and neurodegenerative disorders. Front. Neurosci. 13:778. doi: 10.3389/fnins.2019.00778

Liebner, S., Dijkhuizen, R. M., Reiss, Y., Plate, K. H., Agalliu, D., and Constantin, G. (2018). Functional morphology of the blood-brain barrier in health and disease. Acta Neuropathol. 135, 311-336. doi: 10.1007/s00401-0181815-1

Lindahl, P., Johansson, B. R., Levéen, P., and Betsholtz, C. (1997). Pericyte loss and microaneurysm formation in PDGF-B-deficient mice. Science 277, 242-245. doi: $10.1126 /$ science.277.5323.242

Liu, Q., Yang, Y., and Fan, X. (2020). Microvascular pericytes in brain-associated vascular disease. Biomed. Pharmacother. 121:109633. doi: 10.1016/j.biopha. 2019.109633

Lucke-Wold, B. P., Logsdon, A. F., Turner, R. C., Rosen, C. L., and Huber, J. D. (2014). Aging, the metabolic syndrome, and ischemic stroke: redefining the approach for studying the blood-brain barrier in a complex neurological disease. Adv Pharmacol. 71, 411-449. doi: 10.1016/bs.apha.2014.07.001

Ma, Q., Zhao, Z., Sagare, A. P., Wu, Y., Wang, M., Owens, N. C., et al. (2018). Blood-brain barrier-associated pericytes internalize and clear aggregated amyloid- $\beta 42$ by LRP1-dependent apolipoprotein $\mathrm{E}$ isoformspecific mechanism. Mol. Neurodegener. 13:57. doi: 10.1186/s13024-0180286-0

Ma, S., Kwon, H. J., and Huang, Z. (2012). A functional requirement for astroglia in promoting blood vessel development in the early postnatal brain. PLoS One 7:e48001. doi: 10.1371/journal.pone.0048001

Main, B. S., Villapol, S., Sloley, S. S., Barton, D. J., Parsadanian, M., Agbaegbu, C., et al. (2018). Apolipoprotein E4 impairs spontaneous blood brain barrier repair following traumatic brain injury. Mol. Neurodegener. 13:17. doi: 10.1186/s13024-018-0249-5

Montagne, A., Barnes, S. R., Sweeney, M. D., Halliday, M. R., Sagare, A. P., Zhao, Z., et al. (2015). Blood-brain barrier breakdown in the aging human hippocampus. Neuron 85, 296-302. doi: 10.1016/j.neuron.2014.12.032

Montagne, A., Nation, D. A., Sagare, A. P., Barisano, G., Sweeney, M. D., Chakhoyan, A., et al. (2020). APOE4 leads to blood-brain barrier dysfunction predicting cognitive decline. Nature 581, 71-76. doi: 10.1038/s41586-020$2247-3$

Montagne, A., Nikolakopoulou, A. M., Zhao, Z., Sagare, A. P., Si, G., Lazic, D., et al. (2018). Pericyte degeneration causes white matter dysfunction in the mouse central nervous system. Nat. Med. 24, 326-337. doi: 10.1038/nm.4482

Moretti, R., and Caruso, P. (2020). Small vessel disease-related dementia: an invalid neurovascular coupling? Int. J. Mol. Sci. 21:1095. doi: 10.3390/ijms21031095

Nakagawa, S., Castro, V., and Toborek, M. (2012). Infection of human pericytes by HIV-1 disrupts the integrity of the blood-brain barrier. J. Cell. Mol. Med. 16, 2950-2957. doi: 10.1111/j.1582-4934.2012.01622.x
Nakagomi, T., Nakano-Doi, A., Kawamura, M., and Matsuyama, T. (2015). Do vascular pericytes contribute to neurovasculogenesis in the central nervous system as multipotent vascular stem cells? Stem Cells Dev. 24, 1730-1739. doi: $10.1089 /$ scd.2015.0039

Nation, D. A., Sweeney, M. D., Montagne, A., Sagare, A. P., D’Orazio, L. M., Pachicano, M., et al. (2019). Blood-brain barrier breakdown is an early biomarker of human cognitive dysfunction. Nat. Med. 25, 270-276. doi: 10.1038/s41591-018-0297-y

Nelson, A. R., Sagare, M. A., Wang, Y., Kisler, K., Zhao, Z., and Zlokovic, B. V. (2020). Channelrhodopsin excitation contracts brain pericytes and reduces blood flow in the aging mouse brain in vivo. Front. Aging Neurosci. 12:108. doi: $10.3389 /$ fnagi.2020.00108

Neurology Working Group of the Cohorts for Heart and Aging Research in Genomic Epidemiology (CHARGE) Consortium, the Stroke Genetics Network (SiGN) and the International Stroke Genetics Consortium (ISGC). (2016). Identification of additional risk loci for stroke and small vessel disease: a meta-analysis of genome-wide association studies. Lancet Neurol. 15, 695-707. doi: 10.1016/S1474-4422(16)00102-2

Newcombe, E. A., Camats-Perna, J., Silva, M. L., Valmas, N., Huat, T. J., and Medeiros, R. (2018). Inflammation: the link between comorbidities, genetics, and Alzheimer's disease. J. Neuroinflammation 15:276. doi: 10.1186/s12974018-1313-3

Nikolakopoulou, A. M., Montagne, A., Kisler, K., Dai, Z., Wang, Y., Huuskonen, M. T., et al. (2019). Pericyte loss leads to circulatory failure and pleiotrophin depletion causing neuron loss. Nat. Neurosci. 22, 1089-1098. doi: 10.1038/s41593-019-0434-Z

Nikolakopoulou, A. M., Zhao, Z., Montagne, A., and Zlokovic, B. V. (2017). Regional early and progressive loss of brain pericytes but not vascular smooth muscle cells in adult mice with disrupted platelet-derived growth factor receptor- $\beta$ signaling. PLoS One 12:e0176225. doi: 10.1371/journal.pone. 0176225

Nortley, R., Korte, N., Izquierdo, P., Hirunpattarasilp, C., Mishra, A., Jaunmuktane, Z., et al. (2019). Amyloid $\beta$ oligomers constrict human capillaries in Alzheimer's disease via signaling to pericytes. Science 365:eaav9518. doi: 10.1126/science.aav9518

Obermeier, B., Daneman, R., and Ransohoff, R. M. (2013). Development, maintenance and disruption of the blood-brain barrier. Nat. Med. 19, 1584-1596. doi: 10.1038/nm.3407

Ortiz, G. G., Pacheco-Moisés, F. P., Macías-Islas, M. Á., Flores-Alvarado, L. J., Mireles-Ramírez, M. A., González-Renovato, E. D., et al. (2014). Role of the blood-brain barrier in multiple sclerosis. Arch. Med. Res. 45, 687-697. doi: 10.1016/j.arcmed.2014.11.013

Palmer, A. L., and Ousman, S. S. (2018). Astrocytes and aging. Front. Aging Neurosci. 10, 337-337. doi: 10.3389/fnagi.2018.00337

Paredes, I., Himmels, P., and Ruiz de Almodóvar, C. (2018). Neurovascular communication during CNS development. Dev. cell 45, 10-32. doi: 10.1016/j. devcel.2018.01.023

Persidsky, Y., Hill, J., Zhang, M., Dykstra, H., Winfield, M., Reichenbach, N. L., et al. (2016). Dysfunction of brain pericytes in chronic neuroinflammation. J. Cereb. Blood Flow Metab. 36, 794-807. doi: 10.1177/0271678X1 5606149

Peters, A., Josephson, K., and Vincent, S. L. (1991). Effects of aging on the neuroglial cells and pericytes within area 17 of the rhesus monkey cerebral cortex. Anat. Rec. 229, 384-398. doi: 10.1002/ar.1092290311

Pfister, F., Feng, Y., Hagen, F. V., Hoffmann, S., Molema, G., Hillebrands, J. L., et al. (2008). Pericyte migration: a novel mechanism of pericyte loss in experimental diabetic retinopathy. Diabetes 57, 2495-2502. doi: 10.2337/ $\mathrm{db} 08-0325$

Pfister, F., Lin, J., and Hammes, H.-P. (2010). "Pericyte loss in the diabetic retina," in Experimental Approaches to Diabetic Retinopathy, eds H.-P. Hammes and M. Porta (Basel: Karger), 61-78. doi: 10.1159/000262662

Picoli, C. C., Coimbra-Campos, L. M. C., Guerra, D. A. P., Silva, W. N., Prazeres, P. H. D. M., Costa, A. C., et al. (2019). Pericytes act as key players in spinal cord injury. Am. J. Pathol. 189, 1327-1337. doi: 10.1016/j.ajpath.2019. 03.008

Prazeres, P. H. D. M., Almeida, V. M., Lousado, L., Andreotti, J. P., Paiva, A. E., Santos, G. S. P., et al. (2018). Macrophages generate pericytes in the developing brain. Cell. Mol. Neurobiol. 38, 777-782. doi: 10.1007/s10571-017-0549-2 
Reyahi, A., Nik, A. M., Ghiami, M., Gritli-Linde, A., Pontén, F., Johansson, B. R., et al. (2015). Foxf2 is required for brain pericyte differentiation and development and maintenance of the blood-brain barrier. Dev. Cell 34, 19-32. doi: 10.1016/j.devcel.2015.05.008

Rhea, E. M., and Banks, W. A. (2019). Role of the blood-brain barrier in central nervous system insulin resistance. Front. Neurosci. 13:521. doi: 10.3389/fnins. 2019.00521

Rosenberg, G. A. (2014). Blood-brain barrier permeability in aging and Alzheimer's disease. J. Prev. Alzheimers Dis. 1, 138-139. doi: 10.14283/jpad. 2014.25

Rustenhoven, J., Jansson, D., Smyth, L. C., and Dragunow, M. (2017). Brain pericytes as mediators of neuroinflammation. Trends Pharmacol. Sci. 38, 291-304. doi: 10.1016/j.tips.2016.12.001

Sagare, A. P., Bell, R. D., Zhao, Z., Ma, Q., Winkler, E. A., Ramanathan, A., et al. (2013). Pericyte loss influences Alzheimer-like neurodegeneration in mice. Nat. Commun. 4:2932. doi: 10.1038/ncomms3932

Sagare, A. P., Sweeney, M. D., Makshanoff, J., and Zlokovic, B. V. (2015). Shedding of soluble platelet-derived growth factor receptor- $\beta$ from human brain pericytes. Neurosci. Lett. 607, 97-101. doi: 10.1016/j.neulet.2015. 09.025

Semple, B. D., Blomgren, K., Gimlin, K., Ferriero, D. M., and NobleHaeusslein, L. J. (2013). Brain development in rodents and humans: identifying benchmarks of maturation and vulnerability to injury across species. Prog. Neurobiol. 106-107, 1-16. doi: 10.1016/j.pneurobio.2013.04.001

Shibata, M., Yamada, S., Kumar, S. R., Calero, M., Bading, J., Frangione, B., et al. (2000). Clearance of Alzheimer's amyloid- $\beta(1-40)$ peptide from brain by LDL receptor-related protein-1 at the blood-brain barrier. J. Clin. Invest. 106, 1489-1499. doi: 10.1172/JCI10498

Sims, D. E. (2000). Diversity within pericytes. Clin. Exp. Pharmacol. Physiol. 27, 842-846. doi: 10.1046/j.1440-1681.2000.03343.x

Sweeney, M. D., Ayyadurai, S., and Zlokovic, B. V. (2016). Pericytes of the neurovascular unit: key functions and signaling pathways. Nat. Neurosci. 19, 771-783. doi: 10.1038/nn.4288

Sweeney, M. D., Sagare, A. P., and Zlokovic, B. V. (2015). Cerebrospinal fluid biomarkers of neurovascular dysfunction in mild dementia and Alzheimer's disease. J. Cereb. Blood Flow Metab. 35, 1055-1068. doi: 10.1038/jcbfm. 2015.76

Sweeney, M. D., Sagare, A. P., and Zlokovic, B. V. (2018a). Blood-brain barrier breakdown in Alzheimer disease and other neurodegenerative disorders. Nat. Rev. Neurol. 14, 133-150. doi: 10.1038/nrneurol.2017.188

Sweeney, M. D., Zhao, Z., Montagne, A., Nelson, A. R., and Zlokovic, B. V. (2018b). Blood-brain barrier: from physiology to disease and back. Physiol. Rev. 99, 21-78. doi: 10.1152/physrev.00050.2017

Sweeney, M. D., Sagare, A. P., Pachicano, M., Harrington, M. G., Joe, E., Chui, H. C., et al. (2020). A novel sensitive assay for detection of a biomarker of pericyte injury in cerebrospinal fluid. Alzheimers Dement. 16, 821-830. doi: 10.1002/alz.12061

Teichert, M., Milde, L., Holm, A., Stanicek, L., Gengenbacher, N., Savant, S., et al. (2017). Pericyte-expressed Tie2 controls angiogenesis and vessel maturation. Nat. Commun. 8:16106. doi: 10.1038/ncomms16106

Trost, A., Lange, S., Schroedl, F., Bruckner, D., Motloch, K. A., Bogner, B., et al. (2016). Brain and retinal pericytes: origin, function and role. Front. Cell. Neurosci. 10:20. doi: 10.3389/fncel.2016.00020

Uddin, M. S., Kabir, M. T., Al Mamun, A., Abdel-Daim, M. M., Barreto, G. E., and Ashraf, G. M. (2019). APOE and Alzheimer's disease: evidence mounts that targeting APOE4 may combat Alzheimer's pathogenesis. Mol. Neurobiol. 56, 2450-2465. doi: 10.1007/s12035-018-1237-z

Uemura, M. T., Maki, T., Ihara, M., Lee, V. M. Y., and Trojanowski, J. Q. (2020). Brain microvascular pericytes in vascular cognitive impairment and dementia. Front. Aging Neurosci. 12:80. doi: 10.3389/fnagi.2020.00080

Valdor, R., García-Bernal, D., Riquelme, D., Martinez, C. M., Moraleda, J. M., Cuervo, A. M., et al. (2019). Glioblastoma ablates pericytes antitumor immune function through aberrant up-regulation of chaperone-mediated autophagy. Proc. Natl. Acad. Sci. U S A 116, 20655-20665. doi: 10.1073/pnas.19035 42116

Valles, S. L., Iradi, A., Aldasoro, M., Vila, J. M., Aldasoro, C., de la Torre, J., et al. (2019). Function of glia in aging and the brain diseases. Int. J. Med. Sci. 16, 1473-1479. doi: 10.7150/ijms.37769
Vanlandewijck, M., He, L., Mäe, M. A., Andrae, J., Ando, K., Del Gaudio, F., et al. (2018). A molecular atlas of cell types and zonation in the brain vasculature. Nature 554, 475-480. doi: 10.1038/nature25739

Villaseñor, R., Kuennecke, B., Ozmen, L., Ammann, M., Kugler, C., Grüninger, F., et al. (2017). Region-specific permeability of the bloodbrain barrier upon pericyte loss. J. Cereb. Blood Flow Metab. 37, 3683-3694. doi: 10.1177/0271678X17697340

Wang, Y., Pan, L., Moens, C. B., and Appel, B. (2014). Notch3 establishes brain vascular integrity by regulating pericyte number. Development 141, 307-317. doi: 10.1242/dev.096107

Wilhelm, I., Nyúl-Tóth, Á., Suciu, M., Hermenean, A., and Krizbai, I. A. (2016). Heterogeneity of the blood-brain barrier. Tissue Barriers 4:e1143544. doi: 10.1080/21688370.2016.1143544

Winkler, E. A., Bell, R. D., and Zlokovic, B. V. (2011). Central nervous system pericytes in health and disease. Nat. Neurosci. 14, 1398-1405. doi: 10.1038/ nn.2946

Winkler, E. A., Sengillo, J. D., Bell, R. D., Wang, J., and Zlokovic, B. V. (2012). Blood-spinal cord barrier pericyte reductions contribute to increased capillary permeability. J. Cereb. Blood Flow Metab. 32, 1841-1852. doi: 10.1038/jcbfm. 2012.113

Winkler, E. A., Sengillo, J. D., Sullivan, J. S., Henkel, J. S., Appel, S. H., and Zlokovic, B. V. (2013). Blood-spinal cord barrier breakdown and pericyte reductions in amyotrophic lateral sclerosis. Acta Neuropathol. 125, 111-120. doi: 10.1007/s00401-012-1039-8

Ximerakis, M., Lipnick, S. L., Innes, B. T., Simmons, S. K., Adiconis, X., Dionne, D., et al. (2019). Single-cell transcriptomic profiling of the aging mouse brain. Nat. Neurosci. 22, 1696-1708. doi: 10.1038/s41593-019-0491-3

Yamadera, M., Fujimura, H., Inoue, K., Toyooka, K., Mori, C., Hirano, H., et al. (2015). Microvascular disturbance with decreased pericyte coverage is prominent in the ventral horn of patients with amyotrophic lateral sclerosis. Amyotroph. Lateral Scler. Frontotemporal Degener. 16, 393-401. doi: 10.3109/21678421.2015.1011663

Yamamoto, S., Muramatsu, M., Azuma, E., Ikutani, M., Nagai, Y., Sagara, H., et al. (2017). A subset of cerebrovascular pericytes originates from mature macrophages in the very early phase of vascular development in CNS. Sci. Rep. 7:3855. doi: 10.1038/s41598-017-03994-1

Yamazaki, T., and Mukouyama, Y. (2018). Tissue specific origin, development, and pathological perspectives of pericytes. Front. Cardiovasc. Med. 5:78 doi: $10.3389 /$ fcvm.2018.00078

Yang, A. C., Stevens, M. Y., Chen, M. B., Lee, D. P., Stähli, D., Gate, D., et al. (2020). Physiological blood-brain transport is impaired with age by a shift in transcytosis. Nature 583, 425-430. doi: 10.1038/s41586-020-2453-z

Zaitoun, I. S., Wintheiser, C. M., Jamali, N., Wang, S., Suscha, A., Darjatmoko, S. R., et al. (2019). Bcl-2 expression in pericytes and astrocytes impacts vascular development and homeostasis. Sci. Rep. 9:9700. doi: 10.1038/s41598-019-45915-4

Zeisel, A., Hochgerner, H., Lönnerberg, P., Johnsson, A., Memic, F., van der Zwan, J., et al. (2018). Molecular architecture of the mouse nervous system. Cell 174, 999.e22-1014.e22. doi: 10.1016/j.cell.2018.06.021

Zeller, K., Vogel, J., and Kuschinsky, W. (1996). Postnatal distribution of Glut1 glucose transporter and relative capillary density in blood-brain barrier structures and circumventricular organs during development. Dev. Brain Res. 91, 200-208. doi: 10.1016/0165-3806(95) 00177-8

Zlokovic, B. V. (2008). The blood-brain barrier in health and chronic neurodegenerative disorders. Neuron 57, 178-201. doi: 10.1016/j.neuron.2008. 01.003

Conflict of Interest: The authors declare that the research was conducted in the absence of any commercial or financial relationships that could be construed as a potential conflict of interest.

Copyright (c) 2021 Bennett and Kim. This is an open-access article distributed under the terms of the Creative Commons Attribution License (CC BY). The use, distribution or reproduction in other forums is permitted, provided the original author(s) and the copyright owner(s) are credited and that the original publication in this journal is cited, in accordance with accepted academic practice. No use, distribution or reproduction is permitted which does not comply with these terms. 